\title{
Tafenoquine and its potential in the treatment and relapse prevention of Plasmodium vivax malaria: the evidence to date
}

This article was published in the following Dove Press journal:

Drug Design, Development and Therapy

26 July 2016

Number of times this article has been viewed

\author{
Yehenew A Ebstie $1, *$ \\ Solomon M Abay $2, *$ \\ Wondmagegn $T$ Tadesse ${ }^{3}$ \\ Dawit A Ejigu ${ }^{4}$ \\ 'Department of Microbiology, \\ Immunology and Parasitology, \\ ${ }^{2}$ Department of Pharmacology, \\ ${ }^{3}$ Department of Pharmacology and \\ Clinical Pharmacy, School of Medicine, \\ College of Health Sciences, Addis \\ Ababa University, ${ }^{4}$ Department of \\ Pharmacology, St Paul's Hospital \\ Millennium Medical College, Addis \\ Ababa, Ethiopia \\ *These authors contributed equally \\ to this work
}

\begin{abstract}
Despite declining global malaria incidence, the disease continues to be a threat to people living in endemic regions. In 2015, an estimated 214 million new malaria cases and 438,000 deaths due to malaria were recorded. Plasmodium vivax is the second most common cause of malaria next to Plasmodium falciparum. Vivax malaria is prevalent especially in Southeast Asia and the Horn of Africa, with enormous challenges in controlling the disease. Some of the challenges faced by vivax malaria-endemic countries include limited access to effective drugs treating liver stages of the parasite (schizonts and hypnozoites), emergence/ spread of drug resistance, and misperception of vivax malaria as nonlethal. Primaquine, the only 8-aminoquinoline derivative approved by the US Food and Drug Administration, is intended to clear intrahepatic hypnozoites of $P$. vivax (radical cure). However, poor adherence to a prolonged treatment course, drug-induced hemolysis in patients with glucose-6-phosphate dehydrogenase deficiency, and the emergence of resistance make it imperative to look for alternative drugs. Therefore, this review focuses on data accrued to date on tafenoquine and gives insight on the potential role of the drug in preventing relapse and radical cure of patients with vivax malaria.
\end{abstract}

Keywords: vivax malaria, radical cure, schizonts, hypnozoite, primaquine

\section{Introduction}

Among Plasmodium species causing malaria in humans, Plasmodium falciparum and Plasmodium vivax are the most common causes of malaria. Despite progress in reducing global malaria incidence by $37 \%$, an estimated 214 million new cases of malaria and 438,000 deaths caused by the disease were recorded in 2015. Africa was the most severely affected region, with $88 \%$ of global malaria incidence followed by Southeast Asia where $10 \%$ of the global incidence was reported. ${ }^{1-3}$

$P$. vivax is the second most common cause of malaria in humans next to $P$. falciparum. In 2015, an estimated 13.8 million new cases were reported globally. The highest vivax incidence was recorded in Southeast Asia (74\%), followed by the Eastern Mediterranean Region (11\%) and Africa (10\%). ${ }^{2,3}$ Surprisingly, $80 \%$ of global vivax malaria cases were reported from three countries, Ethiopia, India, and Pakistan. ${ }^{1}$ Even though $P$. vivax is widely distributed, its global incidence rate is wrongly perceived to be low. Some factors that explain underestimation of vivax malaria incidence include microscopic misreading as falciparum in co-endemic areas and presence of undetectable parasitemia among symptomatic patients and liver hypnozoites among asymptomatic patients. ${ }^{2,4-11}$
Correspondence: Yehenew A Ebstie Department of Microbiology, Immunology and Parasitology, School of Medicine, College of Health Sciences, Addis Ababa University, Zambia Street, PO Box 9086, Addis Ababa, Ethiopia Tel +25 I 9 I3049270

Email yeh_kiam@yahoo.com 


\section{Hypnozoites and relapse of malaria}

Human infection with Plasmodium species starts when sporozoites are injected into the blood circulation while female Anopheles mosquito feeds on human blood. These sporozoites then migrate shortly to the liver hepatocytes and enter the exoerythrocytic cycle, in which high numbers of schizonts are produced mitotically. Within 5-15 days of liver infection, thousands of merozoites are released and enter blood circulation. The merozoites then infect red blood cells (RBCs), and this constitutes the erythrocytic cycle that repeats many times in a course of single malaria episode. The erythrocytic cycle produces an average of 8-32 new merozoites and gametocytes per infected RBC. When female Anopheles mosquitoes feed on blood of infected individuals, these gametocytes are ingested and begin sporogonic phase in the gut of mosquitoes, thereby perpetuating vivax infection (Figure 1). ${ }^{8,9,12-17}$

However, a few hepatic schizonts of $P$. vivax and Plasmodium ovale hibernate instead of migrating to the vascular RBCs. These dormant stages, called hypnozoites, are capable of reactivation and could cause relapse of malaria weeks, months, or even years after the first malaria episode. ${ }^{8,9,12}$ The underlying mechanisms for reactivation are not thoroughly understood. However, factors related to relapse of malaria include the adaptive trait of the parasites, geographical variations, the presence of other febrile illness, and dose of the injected sporozoites.9,18,19 A pooled analysis of data from studies published in English that included 87,000 patients with acute vivax malaria reported that $\sim 20 \%$ of the patients experienced malaria relapse, with a relapse rate ranging from $0 \%$ to $100 \% .{ }^{19}$ Studies have also identified that the events of vivax relapse are associated with patient and parasite factors..$^{20,21}$

\section{Malaria interventions}

Global malaria incidences reduced from 262 million in 2000 to 214 million in 2015. The World Health Organization has also planned to eliminate malaria in more than 20 countries by 2025 through implementation of integrated malaria control programs that use interventions such as vector control, effective diagnosis, and use of artemisinin-based combinations therapies. ${ }^{1,32,223}$ Moreover, RTS, S, a recombinant protein-based malaria vaccine, which has been approved by the European Medicines Agency, with a protective efficacy of $\sim 26 \%$ in young infants and $36 \%$ in children, ${ }^{24}$ may also be integrated with other tools in malaria control.

\section{Vector control}

In sub-Saharan Africa, $\sim 50 \%$ of the population used either insecticide-treated mosquito nets or indoor residual spraying to prevent malaria in $2013 .^{3,25}$ Despite emergence of

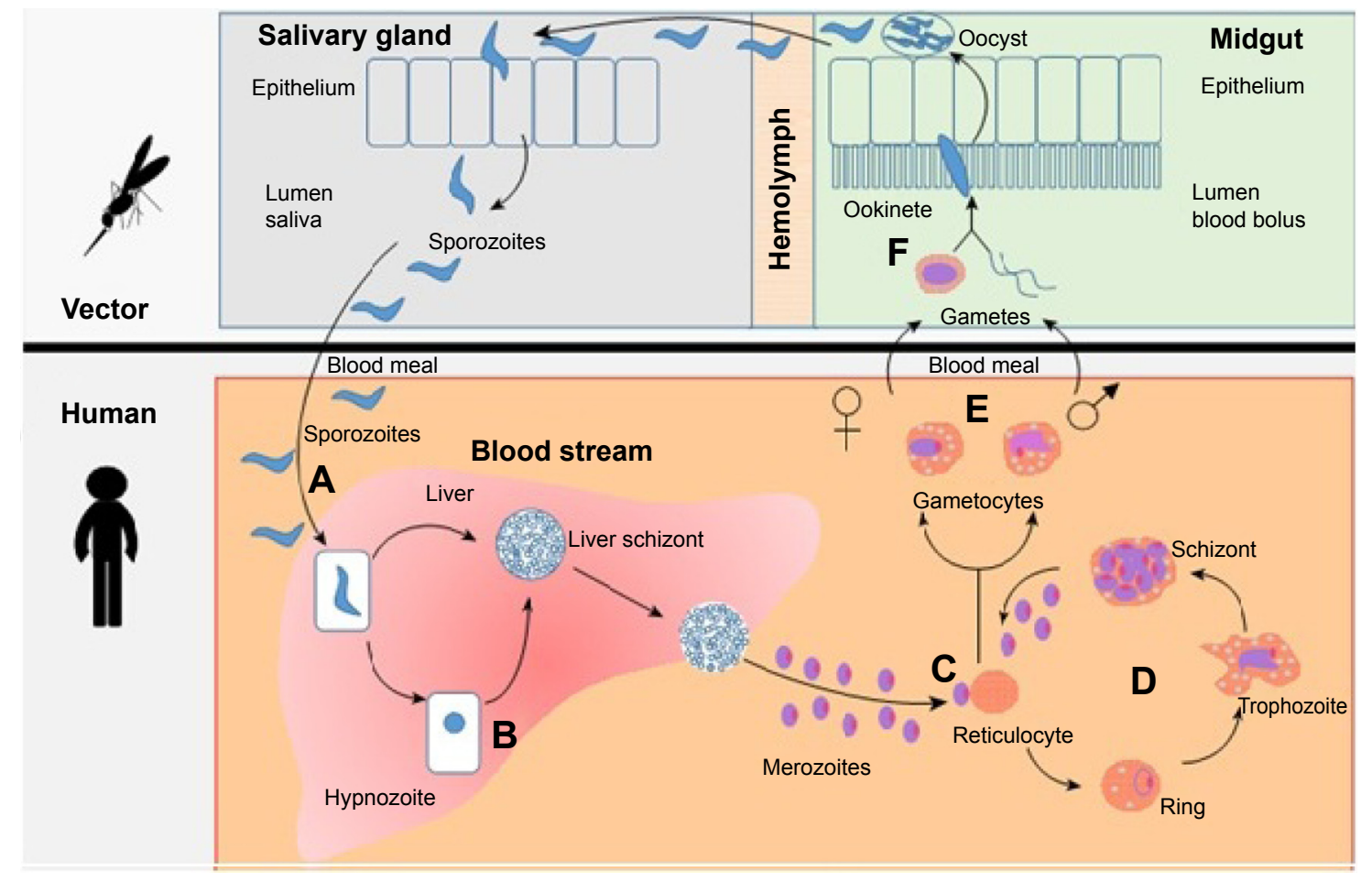

Figure I Life cycle of $P$. vivax and hypnozoite.

Notes: Reproduced with permission from Elsevier. This image was published in Trends Mol Med, 2 I (I2), Popovici J, Ménard D, Challenges in antimalarial drug treatment for vivax malaria control. 776-788. Copyright Elsevier 2015.

Abbreviation: P. vivax, Plasmodium vivax. 
pyrethroid-resistant Anopheles mosquitoes (mainly Anopheles gambiae and Anopheles funestus) worldwide, countries such as Ethiopia, Zambia, and Rwanda have reduced malaria incidence by more than two-thirds compared to what was projected for the countries between 2000 and 2011. Similarly, $4 \%$ of global and $7 \%$ of African populations were protected from malaria by indoor residual spraying in 2013. ${ }^{2,26-30}$

\section{Malaria diagnosis}

Accurate diagnosis and prompt treatment of all patients with proper antimalarial drugs is one of the essential components of malaria control and elimination strategies. Early diagnosis and treatment of acute cases is the primary approach to reduce mortality and morbidity. ${ }^{31,32}$ Diagnosis of malaria is done based on a defined set of criteria. Even though any patient with acute febrile illness should be a malaria suspect, the criteria, particularly the parasite density, may vary with the level of malaria transmission intensity. The World Health Organization also recommends that parasitological confirmation of malaria cases should be done with either microscopy or rapid diagnostic test in order to improve care of parasite-positive patients. ${ }^{33-35}$

Current approaches applied for controlling $P$. falciparum malaria may not be effective against $P$. vivax. Control program against $P$. vivax is proven to be a formidable task due to lack of suitable diagnostic tools to detect low vivax parasitic loads during blood stage, presence of hypnozoites, and lack of effective whole stage drugs against vivax. , $^{2,11,19,36}$

\section{Treatment of uncomplicated vivax}

Chloroquine (CQ) is still the first line of treatment for malaria due to $P$. vivax infection ${ }^{37}$ although CQ-resistant $P$. vivax has been identified in various countries. ${ }^{38}$ A review of ten nonrandomized trials showed that the therapeutic success of CQ at 28 days of follow-up ranges from $49.2 \%$ to $96.2 \% .{ }^{39}$ In addition to $\mathrm{CQ}, P$. vivax and $P$. ovale infections require treatment with primaquine (PQ) for radical cure because of the presence of hypnozoites in their life cycles. In areas with CQ-resistant $P$. vivax, artemisinin-based combinations therapies containing piperaquine, mefloquine, or lumefantrine are the recommended treatments. ${ }^{40,41}$ Artemisinin-based combinations therapies are also effective ${ }^{37,42-44}$ for treatment of malaria due to coinfection with multiple species. ${ }^{43-45}$ Radical treatment with PQ is needed for $P$. vivax or $P$. ovale coinfections. ${ }^{37}$

\section{Treatment of complicated vivax}

$P$. vivax is considered relatively benign disease, ${ }^{46}$ even though manifestations such as severe anemia and acute respiratory distress syndrome are encountered occasionally. ${ }^{47} \mathrm{~A}$ recent

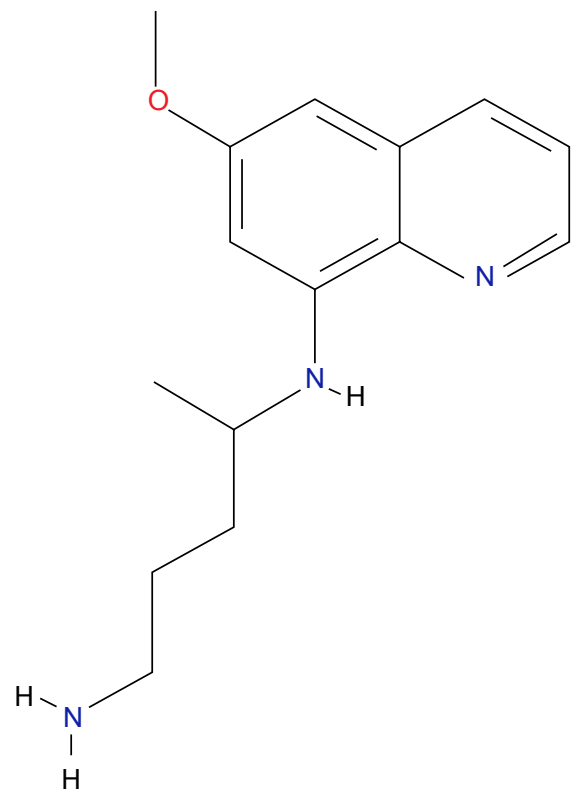

Figure 2 Chemical structure of $\mathrm{PQ} .{ }^{99}$ Abbreviation: $\mathrm{PQ}$, primaquine.

systematic review highlights a marked increase of reported cases of severe vivax in certain $P$. vivax-endemic regions of the world. ${ }^{47}$ Patients with severe vivax malaria are treated aggressively with either parenteral cinchona alkaloids, ie, quinine or quinidine, or artemisinin derivatives, preferably intravenous artesunate. ${ }^{48}$

$P$. vivax infections that recur after drug treatment may be a recrudescent of asexual blood-stage parasites that survived drug treatment, reinfection from new mosquito inoculation, or relapse due to hypnozoites. ${ }^{41}$

Patients with vivax malaria may benefit from the major blood schizonticidal agents only for clinical cure. Similarly, chemoprophylaxis with blood schizonticidal agents provides only suppressive (clinical) prophylaxis. ${ }^{49}$ Hence, a drug targeting the hepatic stages of primary schizonts and secondary schizonts (hypnozoites) would be critical for causal prophylaxis, terminal prophylaxis/presumptive antirelapse therapy (PART), and radical cure of infection caused by vivax malaria. ${ }^{50} \mathrm{PQ}$, a synthetic derivative of quinine, ${ }^{51}$ has been instrumental in these aspects ${ }^{52}$ (Figure 2).

\section{Malaria prophylaxis Causal prophylaxis}

So far, eight clinical studies with different research designs, including experimental challenge studies, controlled trials, and prospective observational studies, have been conducted to evaluate the efficacy of $P Q$ in preventing malaria. The results from these studies showed PQ's protective efficacy against vivax malaria at $30 \mathrm{mg} / \mathrm{d}$ to be $>85 \% .{ }^{50}$ In these 
studies, PQ was started 1 day before travel to an endemic area and continued throughout the stay in the area as well as for 7 days after return. However, PQ is not being used as a causal prophylactic agent in many countries up until now. ${ }^{53}$

\section{Terminal prophylaxis}

Terminal prophylaxis is alternatively called PART. PQ is used for PART with a regimen of $15 \mathrm{mg} / \mathrm{d}$ orally for 14 days immediately after the individuals have traveled out of vivaxendemic areas. ${ }^{54}$ Terminal prophylaxis is considered for persons who have resided for prolonged periods (eg, $\geq 6$ months) in high-risk vivax-endemic areas or who experience intense exposure to $P$. vivax. ${ }^{50}$

\section{Radical cure}

A standard PQ therapy of $15 \mathrm{mg} / \mathrm{d}$ orally for 14 days has been reported to fail in preventing relapse in different geographic locations such as the Solomon Islands, Southeast Asia, Brazil, Colombia, Guyana, Guatemala, Somalia, Ethiopia, Afghanistan, and elsewhere. ${ }^{50,55}$ These reports may not represent actual failures of the $15 \mathrm{mg}$ daily regimen since the extent of adherence to the recommended regimen and quality of the medications were not confirmed in these studies.

A meta-analysis evaluated the efficacy of PQ in preventing vivax malaria recurrence in 59,735 patients. ${ }^{55} \mathrm{~A}$ marked heterogeneity was noted in the study design and particularly on PQ dosing. Despite differences in design, it was possible to draw a conclusion from 87 clinical trials selected for the systematic review. Three dose ranges of $P Q$, expressed as total doses per kilogram, were considered. The dose ranges included very low $(<2.5 \mathrm{mg} / \mathrm{kg}$ body weight), low $(>2.5 \mathrm{mg} / \mathrm{kg}-<5.0 \mathrm{mg} / \mathrm{kg}$ body weight), and high ( $\geq 5.0 \mathrm{mg} / \mathrm{kg}$ body weight). The median rate of recurrence following very low dose of PQ in 44 studies was $25 \%$ (range, 0\%-90\%) at 4-6 months, whereas in 82 studies following low dose of $P Q$, the recurrence was $6.7 \%$ (range, 0\%-59\%) at 4-6 months. High-dose PQ regimens assessed in 28 treatment arms were associated with a median recurrence rate of $0 \%$ (range, $0 \%-15 \%$ ) at 1 month. Some strains of $P$. vivax may also show inherent resistance to $15 \mathrm{mg} / \mathrm{d}$ regimen without any previous exposure to PQ. Taking all these into consideration, higher doses of PQ (30 mg base for 14 days; $420 \mathrm{mg}$ total dose) are administered to prevent relapse in some regions..$^{50,56}$

\section{Why $P Q$ use is not at its maximum?}

Even though PQ was licensed for use in 1952 for the prevention and cure of malaria, its use is not maximized to the need of the society. ${ }^{57}$ The major factor that limits the wide usage of PQ is the high risk of hemolysis in patients with gluocse6-phosphate dehydrogenase (G6PD) deficiency. ${ }^{52}$

\section{Hemolysis related to G6PD deficiency}

Polymorphisms of the G6PD gene are numerous, with G6PD deficiency due to single-point mutations, deletions, insertions, and rarely, splicing variants. ${ }^{58}$ Approximately 400 variant alleles have been described. ${ }^{59}$ The overall prevalence of G6PD deficiency allele across malaria-endemic countries is estimated to be $8.0 \%$ (interquartile range, 7.4-8.8). Using the 2010 population data, this corresponds to 220 million males (interquartile range, 203-241) and an estimated 133 million females (interquartile range, 122-148), including 17 million homozygous females. ${ }^{60}$

Treatment of 22 G6PD-deficient patients in Thailand with a 3-day course of CQ followed by PQ, $15 \mathrm{mg} / \mathrm{d}$ for 14 days, resulted in a significant reduction in hematocrit. The treatment did not result in blood transfusion. ${ }^{61}$ Another report from Brazil revealed the risks of hemolysis in 18 patients who were referred to a tertiary care unit after therapy with PQ $(0.5 \mathrm{mg} / \mathrm{kg} /$ day for 7 days) for radical cure. All patients had jaundice, 14 patients had dark urine, and one patient presented with low urinary output. Blood transfusion was required in 12 out of the 18 patients included in the study due to PQ-induced hemolysis. A patient who developed severe renal failure required hemodialysis. The study confirmed that all the abovementioned adverse phenomena were associated with the patients' G6PD deficiency. ${ }^{62}$ The association between the extent of PQ-induced hemolysis and the dose of PQ as well as degree of G6PD deficiency is well established. ${ }^{40}$ Hence, it is recommended that patients are tested for G6PD deficiency before treatment with PQ and many countries restrict the use of $P Q$, including single-dose treatment, for the gametocidal purpose. ${ }^{63}$

\section{Other adverse effects associated with $\mathrm{PQ}$}

Though not a major reason for abandoning the use of PQ, individuals taking PQ can develop additional adverse effects such as gastrointestinal discomfort and methemoglobinemia. ${ }^{54}$ Administration of 22.5-30 mg of PQ per day resulted in mildto-moderate abdominal cramps in $10 \%-12 \%$ of patients. ${ }^{52}$ Standard PQ therapy elevates methemoglobin levels slightly ${ }^{54}$ and could be treated with intravenous methylene blue. However, in the presence of G6PD deficiency, patients may not respond to treatment. ${ }^{64}$

\section{Need for high dose for a better outcome}

Evidence for failure of the standard PQ regimen, which is $15 \mathrm{mg} / \mathrm{d}$ orally for 14 days, in preventing relapse emerged 
from experimental challenge with the Chesson strain of $P$. vivax. This strain was isolated from an American soldier infected in New Guinea in $1944 .{ }^{65}$ Another trial in Thailand demonstrated reduced efficacy of a $15 \mathrm{mg}$ PQ regimen in preventing relapse. ${ }^{66} \mathrm{~A}$ study in Germany also demonstrated that infection acquired on the islands of New Guinea had a high risk of relapse after PQ therapy. ${ }^{67}$ The higher dose required to tackle PQ-resistant vivax in radical cure or terminal prophylaxis would increase dose-dependent adverse effects from the drug.

\section{Tafenoquine: the next generation 8-aminoquinoline}

Currently available antimalarial drugs are stage specific. Drugs such as PQ have activity mainly on hypnozoites and hence help in preventing relapse, while drugs such as CQ have effect on blood stages (asexual stages), which makes it important for clinical cure of patients with malaria. This fact should attract researchers to work further in discovering and developing products that target multiple stages of the Plasmodium. Efforts are also being exerted to come up with a better alternative drug that can be used in treatment failures due to resistance and that shorten treatment duration. As an example, PQ's liabilities include prolonged treatment duration; increasing trend of failing treatments, particularly at $15 \mathrm{mg} / \mathrm{d}$ regimen; and the risk of hemolytic anemia in G6PDdeficient patients. These identified gaps in PQ treatment should put a pressure on the scientific community to search for alternative interventions that can fill these gaps.

The 8-aminoquinoline tafenoquine (TQ; WR 238605) was discovered by scientists at the Walter Reed Army Institute of Research in 1978. It is currently being developed in a collaborative approach between GlaxoSmithKline and Medicines for Malaria Venture. ${ }^{68}$

\section{Pharmacokinetics of TQ Bioavailability and absorption}

First-time-in-humans safety and pharmacokinetics study showed that the time to peak concentration $\left(t_{\max }\right)$ of TQ is 13.8 hours. This study speculated that the prolonged absorption from the gut could be due to absorption at distal gastrointestinal tract combined with the drug's slow clearance. ${ }^{69}$ In a Phase I trial involving 156 individuals taking different doses of TQ, it was demonstrated that TQ is slowly absorbed. The median $t_{\max }$ values for TQ were 15 hours for the $300 \mathrm{mg}$ dose and 12 hours for the $600 \mathrm{mg}$ and 1,200 mg doses. Area under the curve and maximum concentration observed $\left(C_{\max }\right)$ exhibited moderate intersubject variability. ${ }^{70}$
Bioavailability of TQ increases when the drug is taken with high-fat meal. ${ }^{71}$ From a population kinetics study of TQ in Thai soldiers, it was demonstrated that food affects the amount of TQ absorbed, rather than the rate of absorption. $^{72}$

\section{Distribution}

TQ has a large volume of distribution $(\sim 2,560 \mathrm{~L})$ and a low clearance $(\sim 6 \mathrm{~L} / \mathrm{h}) .{ }^{69}$ Though body weight affects the plasma concentration in general, females tended to achieve higher drug concentrations compared to males of equivalent weight. ${ }^{73}$ The concentration of TQ in whole blood is approximately twofold higher than the corresponding concentration in plasma. In individuals with a normal hematocrit of $45 \%$, the drug concentration in the erythrocytes is estimated to be threefold higher than that in plasma. However, there is no change in accumulation of the drug in RBCs over time. ${ }^{69}$ Little is known about the distribution of TQ to extra vascular tissues in human beings, but animal study showed that the drug is highly distributed to the liver. Area under the curve up to the last measurable concentration $\left(\mathrm{AUC}_{\text {last }}\right)$ in the liver after intravenous administration is $\sim 80$ times more than that in the plasma. ${ }^{74}$

\section{Metabolism and excretion}

Like PQ ${ }^{75}$ the activation of TQ needs metabolism by cytochrome P450 2D6 (CYP2D6) liver microsomal enzyme. ${ }^{76,77}$ This was demonstrated by the lack of the anti-malarial activity of TQ in CYP2D6 knockout mice when given at a dose of $3 \mathrm{mg} / \mathrm{kg}$ and the partial restoration of its antimalarial activity in humanized CYP2D6 knockin mice. ${ }^{76}$

A metabolite of TQ, 5,6 ortho-quinone TQ, has been identified from animals taking the drug (Figure 3 ). The level of 5,6 ortho-quinone TQ is high after administration of TQ in wild-type extensive metabolizer phenotype. This report from laboratory animals shows the association between CYP2D6 metabolism and TQ pharmacokinetics. The findings in the laboratory animals could suggest that TQ is metabolized by CYP2D6 in human beings in whom the isoenzyme shows polymorphism. ${ }^{77}$

\section{Pharmacodynamics of TQ Plasmodium stages affected by TQ}

An in vitro test evaluating the activity of 8-aminoquinolines showed that TQ has an average $50 \%$ inhibitory concentration $\left(\mathrm{IC}_{50}\right)$ of $0.436 \mu \mathrm{M}$ (range, $0.059-1.47 \mu \mathrm{M}$ ) against blood stages of seven P. falciparum clones and strains (NIG59, NIG9171, D6, W2, TM91C235, WR75-235, and TM91C40). ${ }^{78}$ 
A

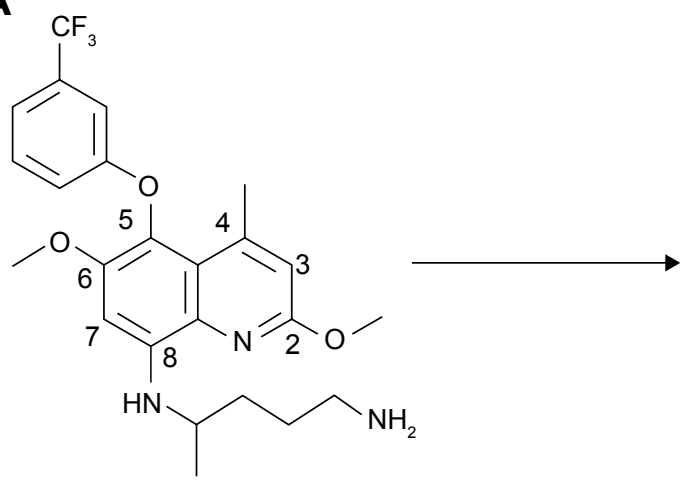

B<smiles>COc1cc(C)c2c(n1)C(NC(C)CCCN)=CC(=O)C2=O</smiles>

Figure 3 Metabolism of TQ (A) to 5,6 ortho-quinone TQ (B) in the presence of 2D6 isoenzyme. ${ }^{77}$ Abbreviation: TQ, tafenoquine.

Another study evaluated an in vitro activity of TQ and PQ in wild isolates of P. falciparum from Djibouti, Gabon, and Senegal, where the isolates are CQ resistant. The $\mathrm{IC}_{50}$ values for TQ were in the range of $0.9-9.7 \mu \mathrm{M}$ for the Djiboutian isolates, $0.6-33.1 \mu \mathrm{M}$ for the Gabonese isolates, and $0.5-20.7 \mu \mathrm{M}$ for the Senegalese isolates. ${ }^{79} \mathrm{PQ}$ 's activities were inferior to those of TQ.

A study from Thailand investigated the transmission blocking potential of TQ. The study evaluated the efficacy of TQ against the sporogonic stage of vivax parasite after letting mosquitoes feed on gametocytemic blood containing TQ. TQ reduced the transmission of the parasite to the mosquito at doses of $\geq 25 \mathrm{mg} / \mathrm{kg}$. ${ }^{80}$

\section{Mechanism of action}

TQ is a prodrug that needs activation to quinone TQ metabolite through metabolism by CYP2D6 (Figure 3) ${ }^{76}$ The mechanism of action of TQ is not yet precisely known. Research Councils UK $^{81}$ demonstrated the metabolites of 8 -aminoquinolines to be redox cycled by $P$. falciparum ferredoxin-NADP+ reductase and diflavin reductase enzymes, which are upregulated in gametocytes and liver stages. The spontaneous oxidation of metabolites also generates hydrogen peroxide and hydroxyl radicals. It is hypothesized that the reactive oxygen species generated through $P$. falciparum ferredoxin-NADP+ reductase and diflavin reductase enzymes leads to parasite kill. ${ }^{81}$ The upregulation of these enzymes in TQ-sensitive stages of the parasite supports the hypothesis.

Similar to the blood schizonticide CQ, TQ inhibits heme polymerase in blood stage of the parasites. ${ }^{78}$ This may explain the reason why TQ has activity against asexual blood stage of parasites, unlike PQ that does not inhibit the polymerization of hematin.

\section{Clinical development of TQ}

TQ, an investigational 8-aminoquinoline derivative for the treatment and relapse prevention of $P$. vivax malaria, has been granted a breakthrough therapy designation by the US Food and Drug Administration. ${ }^{82}$ Breakthrough therapy designation is the US Food and Drug Administration's program aimed at accelerating the development and review times of drugs for serious or life-threatening conditions. The designation was granted since preliminary clinical evidence indicated that TQ has substantial improvement over the existing therapy ${ }^{83}$

\section{Efficacy of TQ in radical cure}

There were six controlled trials published, out of which three were randomized controlled dose selection trials. Subsequently, out of the three randomized trials, only one trial was a doubleblind study ${ }^{84.87}$ High-quality evidence on the efficacy of TQ for radical cure is obtained from this double-blind study, which was also a multicenter, randomized, placebo-controlled Phase IIb study (the Dose and Efficacy Trial Evaluating Chloroquine and Tafenoquine In Vivax Elimination [DETECTIVE] trial). The trial evaluated efficacy of TQ in a range of doses in preventing relapse within 6 months. Single dose of TQ at $600 \mathrm{mg}$, following the standard CQ therapy for clinical cure, prevented relapse of vivax malaria by $91.9 \%$, whereas $15 \mathrm{mg}$ PQ administered for 14 days prevented relapse only by $77.3 \% .{ }^{85}$ The same study reevaluated the efficacy of TQ in homologous vivax strain. The recurrence rate was $3.5 \%$ and $1.8 \%$ at $300 \mathrm{mg}$ and $600 \mathrm{mg}$ single doses of TQ, respectively. At a dose of $300 \mathrm{mg} T Q$, there was a ninefold reduction in homologous recurrence compared with CQ alone. At the same dose of $300 \mathrm{mg}$, heterologous recurrences also reduced by threefold. ${ }^{84}$ The DETECTIVE trial concluded that $50 \mathrm{mg}$ and $100 \mathrm{mg}$ of TQ do not provide a satisfactory prevention of relapse (Table 1). 


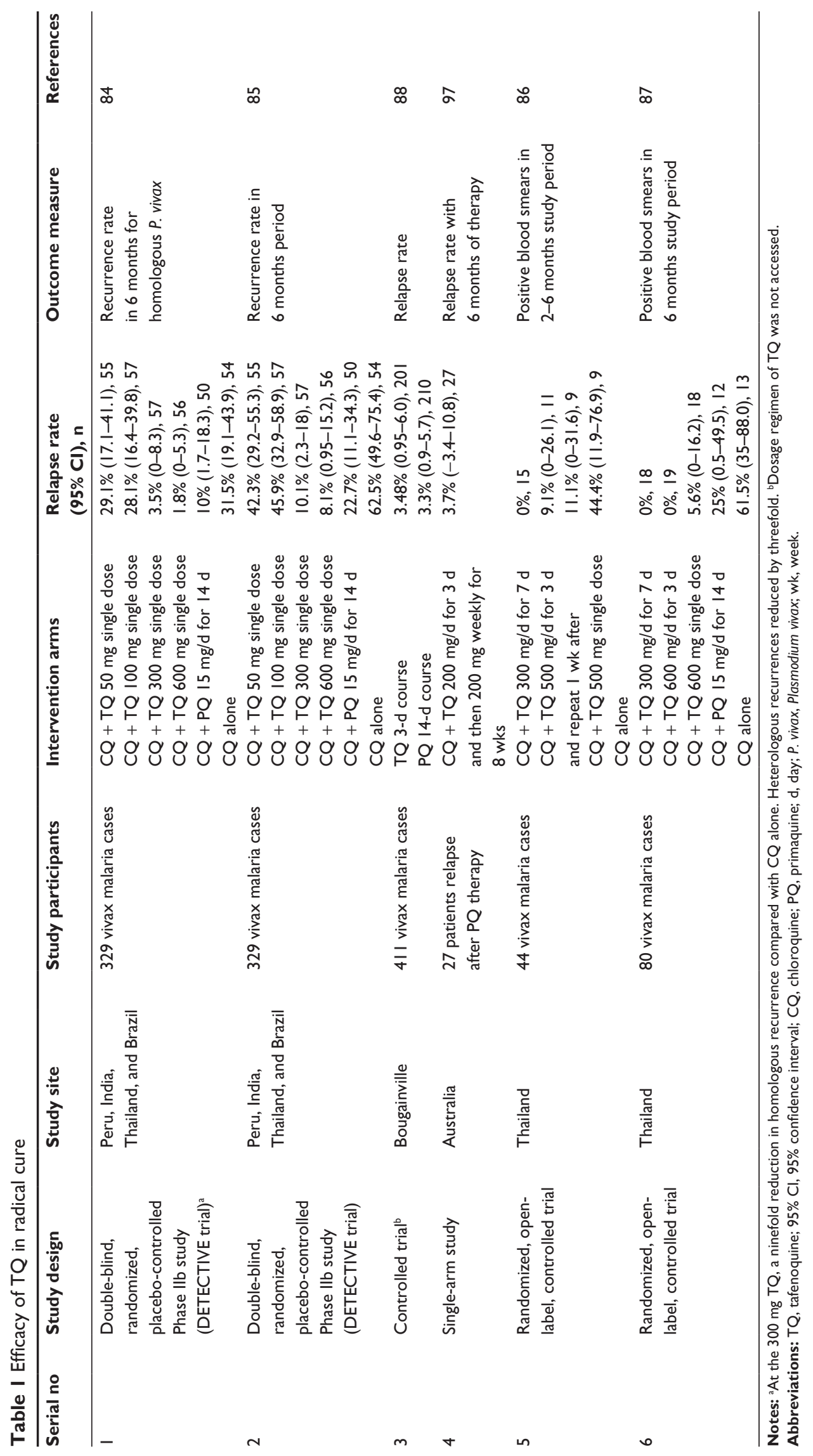


Two open-label controlled trials showed that a single dose of $500 \mathrm{mg}$ or $600 \mathrm{mg}$ of TQ added to the standard dose of CQ reduced the recurrence rate of vivax infection by $75 \%$ and $91.1 \%$, respectively, compared with the control arm treated with CQ alone. ${ }^{86,87}$ Although these studies involved few study participants, the findings were somewhat in agreement with those of the DETECTIVE trial (Table 1).

Trials investigating the effect of repeated doses of TQ to prevent relapse of vivax malaria were also conducted. A 3-day course of TQ was found to be noninferior to a 14-day course of PQ treatment with a relapse rate of $3.48 \%$ and $3.3 \%$, respectively. ${ }^{88}$ Two randomized open-label controlled trials from Thailand also revealed that a 7-day course of TQ after the standard dose of CQ prevented relapse completely (Table 1). ${ }^{86,87}$

\section{Chemoprophylactic efficacy of TQ}

In a human challenge study, administration of TQ (600 mg single dose) 1 day prior to mosquito challenge prevented falciparum infection in three of the four volunteers included in the study. In this study, the volunteer who got infected had a low plasma TQ concentration. ${ }^{89}$ A study on protective efficacy of TQ against falciparum malaria in Ghana revealed that the drug's efficacy ranges from $84.4 \%$ to $87.2 \%$ using a regimen of $50-200 \mathrm{mg} / \mathrm{d}$ for 3 days as loading followed by weekly maintenance doses. Shanks et al support the idea of adding weekly maintenance dose of TQ in the regimen in order to achieve a better efficacy. ${ }^{90,91}$ Another study in Gabon confirms the prophylactic efficacy of TQ at $250 \mathrm{mg}$ for 3 days to be $100 \%$ during a 2-month study period. ${ }^{92}$ Another study in East Timor comparing the chemoprophylactic efficacy of TQ and mefloquine against vivax infection showed that TQ's prophylactic efficacy of $99.1 \%$ was not inferior to that of mefloquine's, which was $99.3 \%$ as shown in Table $2 .{ }^{93}$

\section{Efficacy of TQ for terminal prophylaxis}

Randomized controlled trials evaluated the terminal prophylactic efficacy of TQ in Australian defense force personnel returning from Bougainville and East Timor. ${ }^{94}$ The relapse rate was higher in study participants returning from East Timor than in those returning from Bougainville even though the treatment did not differ in the two locations. This study revealed TQ to be a good drug for PART. TQ administered with a twice daily (bid) dose of $200 \mathrm{mg}$ for 3 days had a similar efficacy to $400 \mathrm{mg}$ of the drug administered once daily for 3 days (Table 3 ). The pooled relapse rate in treatment arms getting the divided dose of $200 \mathrm{mg}$ TQ bid (3.1\%; $85 \%$ confidence interval [CI]: 1-7.1) was not significantly different from that getting the single dose of $400 \mathrm{mg}$ daily $(7.9 \%$; 95\% CI: 4.8-12). ${ }^{94}$

Another trial compared the terminal prophylactic efficacy of $400 \mathrm{mg}$ TQ for 3 days (divided and undivided dose) with PQ (7.5 mg tid for 14 days) in study participants returning from Bougainville. ${ }^{95}$ The relapse rate in the TQ arm was $1.9 \%$ (95\% CI: $0.5-3.3)$, whereas that in the PQ arm was 2.8\% (95\% CI: 0.6-5; Table 3).

\section{Curative efficacy of TQ}

In vitro experiments showed that TQ has antimalarial effect on the blood stage of P. falciparum isolates. The $\mathrm{IC}_{50}$ of TQ against falciparum isolates ranges from $59 \mathrm{nM}$ to $9.7 \mu \mathrm{M}$ from different studies. ${ }^{78,79}$ Evidences support the effect of TQ to be related with the inhibition of heme polymerase. ${ }^{78}$ The reported $\mathrm{IC}_{50}$ of TQ against falciparum isolates were higher than the artesunate $\mathrm{IC}_{50}$ (range, $1.85-2.42 \mathrm{nM}$ ) and lower than the CQ $\mathrm{IC}_{50}$ (range, 104-334 nM). This is explained by the fact that the isolates used for test were resistant to CQ. ${ }^{79}$

An exploratory study investigated the curative efficacy of TQ (400 mg single dose followed by $200 \mathrm{mg}$ bid for 2 days) in two vivax malaria patients after their return from Papua New Guinea. The patients had no positive blood smears during the 2-year follow-up period. The investigators observed that malaria parasites were cleared rapidly. These findings, however, need to be supported by randomized controlled trial(s) before TQ is used for curative purpose. ${ }^{96}$

\section{Safety of TQ}

A study investigating the safety of $200 \mathrm{mg}$ weekly dose of TQ for 6 months in 492 participants showed that 13\% of the participants encountered at least one adverse event. The most frequent complaint was gastrointestinal abnormalities (nausea and abdominal pain). Treatment-related mild vortex keratopathy, corneal deposits, was also detected in 93\% (69 of 74) of subjects taking TQ. The vortex keratopathy was not associated with any effect on visual acuity and was fully resolved in all subjects by 1 year. ${ }^{93}$

Another study assessed possible adverse effects of TQ in 369 participants with a dose range of $25 \mathrm{mg}$ to $200 \mathrm{mg}$ in a weekly prophylactic therapy. Gastrointestinal abnormalities (diarrhea, dysentery, and abdominal pain) were the most common reported adverse events with a frequency ranging from $13 \%$ to $18 \%$. The study also confirmed that there is no evidence of a relationship between TQ dosage and reports of physical complaints or the occurrence of abnormal laboratory 


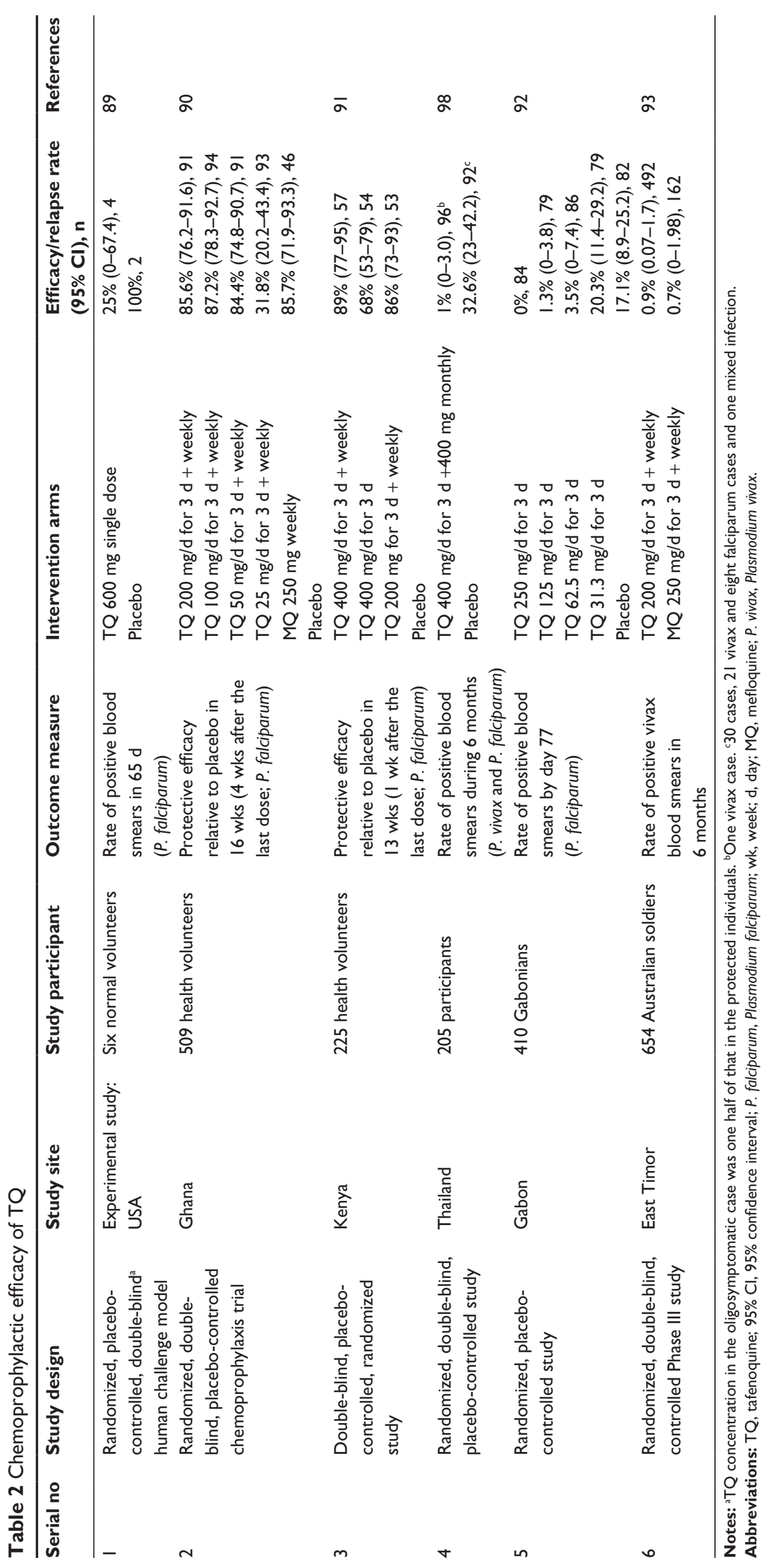


Table 3 Efficacy of TQ in terminal prophylaxis

\begin{tabular}{|c|c|c|c|c|c|c|}
\hline Serial no & Study design & Study participants & $\begin{array}{l}\text { Outcome } \\
\text { measure }\end{array}$ & Intervention arm & $\begin{array}{l}\text { Relapse rate } \\
(95 \% \mathrm{Cl}), \mathrm{n}\end{array}$ & References \\
\hline 1 & $\begin{array}{l}\text { Randomized, } \\
\text { open-label } \\
\text { controlled trial }\end{array}$ & $\begin{array}{l}348 \text { Australian defense } \\
\text { force personnel returning } \\
\text { from Bougainville }\end{array}$ & $\begin{array}{l}\text { Relapse rate } \\
\text { after } 12 \text { months }\end{array}$ & $\begin{array}{l}\text { TQ } 200 \mathrm{mg} \text { bid for } 3 \mathrm{~d} \\
\text { TQ } 400 \mathrm{mg} / \mathrm{d} \text { for } 3 \mathrm{~d} \\
\text { PQ } 7.5 \mathrm{mg} \text { tid + doxycycline } \\
100 \mathrm{mg} / \mathrm{d} \text { for } \mathrm{l} 4 \mathrm{~d}\end{array}$ & $\begin{array}{l}1.2 \%(0.03-6.3), 86 \\
2.3 \%(0.3-8.1), 87 \\
3.4 \%(1.3-7.3), 175\end{array}$ & 94 \\
\hline 2 & $\begin{array}{l}\text { Randomized, } \\
\text { open-label } \\
\text { controlled trial }\end{array}$ & $\begin{array}{l}925 \text { Australian defense } \\
\text { force personnel returning } \\
\text { from Timor-Leste }\end{array}$ & $\begin{array}{l}\text { Relapse rate } \\
\text { after } 12 \text { months }\end{array}$ & $\begin{array}{l}\text { TQ } 200 \mathrm{mg} \text { qd for } 3 \mathrm{~d} \\
\text { TQ } 200 \mathrm{mg} \text { bid for } 3 \mathrm{~d} \\
\text { TQ } 400 \mathrm{mg} \text { qd for } 3 \mathrm{~d} \\
\text { PQ } 7.5 \mathrm{mg} \text { tid + doxycycline } \\
\text { 100/d for } 14 \mathrm{~d}\end{array}$ & $\begin{array}{l}4.9 \%(3-7.5), 406 \\
5.3 \%(1.5-13.1), 75 \\
11 \%(6.5-17), 155 \\
10 \%(6.8-14.1), 289\end{array}$ & 94 \\
\hline 3 & $\begin{array}{l}\text { Randomized, } \\
\text { controlled trial }\end{array}$ & $\begin{array}{l}592 \text { Australian defense } \\
\text { personnel volunteers } \\
\text { returning from Bougainville }\end{array}$ & $\begin{array}{l}\text { Positive blood } \\
\text { smear within } \\
12 \text { months }\end{array}$ & $\begin{array}{l}\text { TQ } 200 \mathrm{mg} \text { bid or } \\
400 \mathrm{mg} / \mathrm{d} \text { for } 3 \mathrm{~d} \\
\text { PQ } 22.5 \mathrm{mg} \text { for } 14 \mathrm{~d}\end{array}$ & $\begin{array}{l}1.9 \%(0.5-3.3), 378 \\
2.8 \%(0.6-5), 214\end{array}$ & 95 \\
\hline
\end{tabular}

Abbreviations: TQ, tafenoquine; $95 \% \mathrm{Cl}, 95 \%$ confidence interval; d, day; PQ, primaquine; bid, twice daily; tid, three times daily; qd, once daily.

parameters. The laboratory parameters assessed in the study were alanine aminotransferase, hemoglobin, white blood cell counts, platelet counts, and bilirubin levels. ${ }^{90}$

Study participants included in the clinical trial of TQ are screened for normal level of G6PD activity. A single study reported hemolytic anemia in study participants with G6PD deficiency who were wrongly recruited in a TQ trial. ${ }^{91}$

Prolongation of the QT interval is also one of the concerns in patients treated with antimalarial drugs. In the DETECTIVE trial, QT prolongation occurred in $2 \%$ of patients taking TQ, while the phenomenon was observed in $8 \%$ and $4 \%$ of patients taking PQ and CQ, respectively. ${ }^{85}$ In another study, ${ }^{70} \mathrm{TQ}$ did not cause prolongation of QT interval even at a dose of 1,200 mg. Hence, TQ could be taken as a safer drug in terms of QT prolongation compared with other quinoline antimalarial drugs probably due to short duration of treatment with TQ. ${ }^{70}$

\section{Conclusion}

The conclusions of this review are as follows:

1. TQ is an efficacious drug for radical cure, terminal prophylaxis, and chemoprophylaxis of vivax malaria. TQ has at least similar efficacy to PQ for radical cure and terminal prophylaxis with the additional benefit of short treatment duration, which can significantly improve patient adherence. A weekly administration of TQ also demonstrated equivalent chemoprophylactic efficacy with that of mefloquine.

2. Most of TQ efficacy studies are conducted in individuals with normal G6PD activity. However, one clinical study reported severe hemolytic anemia in G6PD-deficient individuals who were wrongly included in the study. Data on the relative safety of TQ over PQ in patients with G6PD deficiency are lacking.
3. Though TQ has a better activity against clinical isolates of blood stage $P$. vivax parasite in vitro compared to PQ and $C Q$, there is not enough evidence supporting its use for clinical cure.

The authors recommend further multicenter clinical studies on TQ with appropriate sample size and considering special populations before labeling TQ as an alternative medication for radical cure, terminal prophylaxis, and chemoprophylaxis of vivax malaria. Additional studies might be also required to investigate possible drug interactions with TQ.

\section{Acknowledgments}

The authors would like to thank Addis Ababa University for providing articles. The authors declare that there is no financial support for the current review.

\section{Author contributions}

All authors contributed toward data analysis, drafting and critically revising the paper and agree to be accountable for all aspects of the work.

\section{Disclosure}

The authors report no conflicts of interest in this work.

\section{References}

1. World Health Organization. World Malaria Report 2015. Geneva: World Health Organization; 2015.

2. World Health Organization. World Malaria Report 2014. Vol. 55. Geneva: World Health Organization; 2014.

3. World Health Organization. Global Technical Strategy for Malaria 2016-2030. Geneva: World Health Organization; 2015.

4. Battle KE, Gething PW, Elyazar IRF, et al. The Global Public Health Significance of Plasmodium Vivax. Vol. 80. Amsterdam: Elsevier; 2012. 
5. Naing C, Whittaker MA, Nyunt Wai V, Mak JW. Is Plasmodium vivax malaria a severe malaria?: a systematic review and meta-analysis. PLoS Negl Trop Dis. 2014;8(8):e3071.

6. Carlton JM, Adams JH, Silva JC, et al. Comparative genomics of the neglected human malaria parasite Plasmodium vivax. Nature. 2008; 455(7214):757-763.

7. Baird JK. Resistance to therapies for infection by Plasmodium vivax. Clin Microbiol Rev. 2009;22(3):508-534.

8. Popovici J, Ménard D. Challenges in antimalarial drug treatment for vivax malaria control. Trends Mol Med. 2015;21(12):776-788.

9. Price RN, Tjitra E, Guerra CA, et al; UKPMC Funders Group. Vivax malaria: neglected and not benign. Am J Trop Med Hyg. 2007;77(6): 79-87.

10. Bhardwaj M, Bharadwaj L, Trigunayat K, Trigunayat MM. Thermal characterization of Plasmodium falciparum species specific proteins in Indian geographical area. Nat Preced. 2010. Available from: http:// precedings.nature.com/documents/4565/version/1. Accessed July 28, 2016.

11. Lacerda MV, Mourão MP, Alexandre MA, et al. Understanding the clinical spectrum of complicated Plasmodium vivax malaria: a systematic review on the contributions of the Brazilian literature. Malar J. 2012;11:12.

12. Guerin PJ, Olliaro P, Nosten F, et al. Malaria: current status of control, diagnosis, treatment, and a proposed agenda for research and development. Lancet Infect Dis. 2002;2(9):564-573.

13. Flannery EL, Chatterjee AK, Winzeler EA. Antimalarial drug discoveryapproaches and progress towards new medicines. Nat Rev Microbiol. 2013;11(12):849-862.

14. Kheng S, Muth S, Taylor WR, et al. Tolerability and safety of weekly primaquine against relapse of Plasmodium vivax in Cambodians with glucose-6-phosphate dehydrogenase deficiency. BMC Med. 2015;13(1): $1-10$.

15. Val FF, Sampaio VS, Cassera MB, et al. Plasmodium vivax malaria elimination: should innovative ideas from the past be revisited? Mem Inst Oswaldo Cruz. 2014;109(5):522-524.

16. Collins WE, Jeffery GM. Primaquine resistance in Plasmodium vivax. Am J Trop Med Hyg. 1996;55(3):243-249.

17. Cowman AF, Berry D, Baum J. The cellular and molecular basis for malaria parasite invasion of the human red blood cell. J Cell Biol. 2012 198(6):961-971.

18. White MT, Karl S, Battle KE, Hay SI, Mueller I, Ghani AC. Modelling the contribution of the hypnozoite reservoir to Plasmodium vivax transmission. Elife. 2014;3:e04692.

19. White NJ. Determinants of relapse periodicity in Plasmodium vivax malaria. Malar J. 2011;10(1):297.

20. Velho DP, Alves-jr ER, Ribatski-silva D, Gomes LT. Factors associated with recurrent Plasmodium vivax malaria in Porto Velho, Rondônia State, Brazil. Cad Saude Publica. 2014;30(7):1403-1417.

21. Chen N, Auliff A, Rieckmann K, Gatton M, Cheng Q. Relapses of Plasmodium vivax infection result from clonal hypnozoites activated at predetermined intervals. J Infect Dis. 2007;195(7):934-941.

22. Pindolia DK, Garcia AJ, Huang Z, et al. The demographics of human and malaria movement and migration patterns in East Africa. Malar J. $2013 ; 12: 397$

23. World Health Organization. Control and Elimination of Plasmodium vivax Malaria: A Technical Brief. Vol. 17. Geneva: World Health Organization; 2015.

24. RTS S Clinical Trials Partnership. Efficacy and safety of RTS, S/AS01 malaria vaccine with or without a booster dose in infants and children in Africa: final results of a phase 3, individually randomized, controlled trial. Lancet. 2015;386(9988):31-45.

25. World Health Organization. Reversing the Incidence of Malaria 2000-2015. Geneva: World Health Organization; 2015.

26. United Nations. The Millennium Development Goals Report 2014. New York: United Nations; 2014.

27. Aregawi M, Lynch M, Bekele W, et al. Time series analysis of trends in malaria cases and deaths at hospitals and the effect of antimalarial interventions, 2001-2011, Ethiopia. PLoS One. 2014;9(11):e106359.
28. Roll Back Malaria Partnership. World Malaria Day-Asia, April 2014. Geneva: Roll Back Malaria Partnership; 2015.

29. Karema C, Aregawi MW, Rukundo A, et al. Trends in malaria cases, hospital admissions and deaths following scale-up of anti-malarial interventions, 2000-2010, Rwanda. Malar J. 2012;11:236.

30. Masaninga F, Chanda E, Chanda-kapata P, et al. Review of the malaria epidemiology and trends in Zambia. Asian Pac J Trop Biomed. 2013; 3(2):89-94.

31. World Health Organization. Malaria: Global Fund Proposal Development. Geneva: World Health Organization; 2011:1-20.

32. Ukpe IS, Moonasar D, Raman J, Barnes KI, Baker L, Blumberg L. Case management of malaria: treatment and chemoprophylaxis. $S$ Afr Med J. 2014;103(10):793-798.

33. Wilson ML. Laboratory diagnosis of malaria: conventional and rapid diagnostic methods. Arch Pathol Lab Med. 2013;137(6):805-811.

34. World Health Organization. Parasitological Confirmation of Malaria Diagnosis. Geneva: World Health Organization; 2009.

35. World Health Organization. Universal Access to Malaria Diagnostic Testing: An Operational Manual. Vol. 12. Geneva: World Health Organization; 2013.

36. Battle KE, Karhunen MS, Bhatt S, et al. Geographical variation in Plasmodium vivax relapse. Malar J. 2014;13(1):144.

37. World Health Organization. Guidelines for the Treatment of Malaria. 2nd ed. Geneva: World Health Organization; 2010.

38. Eibach D, Ceron N, Krishnalall K, et al. Therapeutic efficacy of artemether-lumefantrine for Plasmodium vivax infections in a prospective study in Guyana. Malar J. 2012;11:347.

39. Naing C, Aung K, Win DK, Wah MJ. Efficacy and safety of chloroquine for treatment in patients with uncomplicated Plasmodium vivax infections in endemic countries. Trans R Soc Trop Med Hyg. 2010;104(11):695-705.

40. World Health Organization. Guidelines for the Treatment of Malaria. 3rd ed. Geneva: World Health Organization; 2015.

41. Imwong M, Snounou G, Pukrittayakamee S, et al. Relapses of Plasmodium vivax infection usually result from activation of heterologous hypnozoites. J Infect Dis. 2007;195(7):927-933.

42. Douglas NM, Anstey NM, Angus BJ, Nosten F, Price RN. Europe PMC Funders Group artemisinin combination therapy for vivax malaria? Lancet Infect Dis. 2012;10(6):405-416.

43. Mekonnen SK, Aseffa A, Medhin G, Berhe N, Velavan TP. Re-evaluation of microscopy confirmed Plasmodium falciparum and Plasmodium vivax malaria by nested PCR detection in southern Ethiopia. Malar J. 2014; 13(1):48.

44. Senn H, Alattas N, Boggild AK, Morris SK. Mixed-species Plasmodium falciparum and Plasmodium ovale malaria in a paediatric returned traveller. Malar J. 2014;13(1):78.

45. Zakeri S, Kakar Q, Ghasemi F, et al. Detection of mixed Plasmodium falciparum \& Plasmodium vivax infections by nested-PCR in Pakistan, Iran \& Afghanistan. Indian J Med Res. 2010;132:31-35.

46. Nicholas DM, John GK, von Seidlein L, Nicholas AM, Ric PN. Chemotherapeutic Strategies for Reducing Transmission of Plasmodium vivax Malaria. Vol. 80. Amsterdam: Elsevier; 2012.

47. Rahimi BA, Thakkinstian A, White NJ, Sirivichayakul C, Dondorp AM, Chokejindachai W. Severe vivax malaria : a systematic review and metaanalysis of clinical studies since 1900. Malar J. 2014;13(1):1-10.

48. Pasvol G. The treatment of complicated and severe malaria. $\mathrm{Br}$ Med Bull. 2006;75-76(1):29-47.

49. Baird JK, Schwartz E, Hoffman SL. Prevention and treatment of vivax malaria. Curr Infect Dis Rep. 2007;9(1):39-46.

50. Hill DR, Baird JK, Parise ME, Lewis LS, Ryan ET, Magill AJ. Primaquine: report from CDC expert meeting on malaria chemoprophylaxis I. Am J Trop Med Hyg. 2006;75(3):402-415.

51. Hobbs C, Duffy P. Drugs for malaria: something old, something new, something borrowed. F1000 Biol Rep. 2011;3:24

52. Vale N, Moreira R, Gomes P. Primaquine revisited six decades after its discovery. Eur J Med Chem. 2009;44(3):937-953.

53. Baird JK. Suppressive chemoprophylaxis invites avoidable risk of serious illness caused by Plasmodium vivax malaria. Travel Med Infect Dis. 2013;11(1):60-65. 
54. Baird JK, Fryauff DJ, Hoffman SL. Primaquine for prevention of malaria in travelers. Clin Infect Dis. 2003;37(12):1659-1667.

55. John GK, Douglas NM, von Seidlein L, et al. Primaquine radical cure of Plasmodium vivax: a critical review of the literature. Malar J. 2012;11(1):280.

56. Campo B, Vandal O, Wesche DL, Burrows JN. Killing the hypnozoitedrug discovery approaches to prevent relapse in Plasmodium vivax. Pathog Glob Health. 2015;109(3):107-122.

57. Fernando D, Rodrigo C, Rajapakse S. Primaquine in vivax malaria: an update and review on management issues. Malar J. 2011; 10(1):351.

58. Beutler E, Duparc S; G6PD Deficiency Working Group. Glucose6-phosphate dehydrogenase deficiency and antimalarial drug development. Am J Trop Med Hyg. 2007;77(4):779-789.

59. Carter N, Pamba A, Duparc S, Waitumbi JN. Frequency of glucose6-phosphate dehydrogenase deficiency in malaria patients from six African countries enrolled in two randomized anti-malarial clinical trials. Malar J. 2011;10(1):241.

60. Howes RE, Piel FB, Patil AP, et al. G6PD deficiency prevalence and estimates of affected populations in malaria endemic countries: a geostatistical model-based map. PLoS Med. 2012;9(11): e1001339.

61. Buchachart K, Krudsood S, Singhasivanon P, et al. Effect of primaquine standard dose (15 mg/day for 14 days) in the treatment of vivax malaria patients in Thailand. Southeast Asian J Trop Med Public Health. 2001; 32(4):720-726.

62. Ramos Júnior WM, Sardinha JF, Costa MR, Santana MS, Alecrim MG, Lacerda MV. Clinical aspects of hemolysis in patients with Plasmodium vivax malaria treated with primaquine, in the Brazilian Amazon. Braz J Infect Dis. 2010;14(4):410-412.

63. World Health Organization. The Safety and Effectiveness of Single Dose Primaquine as a Plasmodium falciparum Gametocytocide. Geneva: World Health Organization; 2012:1-19.

64. Coleman M, Coleman N. Drug-induced methaemoglobinaemia. Treatment issues. Drug Saf. 1996;14(6):394-405.

65. Baird JK, Hoffman SL. Primaquine therapy for malaria. Clin Infect Dis. 2004;39(9):1336-1345.

66. Bunnag D, Karbwang J, Thanavibul A, et al. High dose of primaquine in primaquine resistant vivax malaria. Trans R Soc Trop Med Hyg. 1994; 88(2):218-219.

67. Jelinek T, Nothdurft HD, Von Sonnenburg F, Loscher T. Long-term efficacy of primaquine in the treatment of vivax malaria in nonimmune travelers. Am J Trop Med Hyg. 1995;52(4):322-324.

68. GlaxoSmithKline [webpage on the Internet]. GSK and MMV Announce Start of Phase III Programme of Tafenoquine for Plasmodium vivax Malaria. 2014:1-3. Available from: https://us.gsk.com/en-us/media/ press-releases/2014/gsk-and-mmv-announce-start-of-phase-iiiprogramme-of-tafenoquine-for-plasmodium-vivax-malaria/. Accessed July 28, 2016.

69. Brueckner RP, Lasseter KC, Lin ET, Schuster BG. First-time-in-humans safety and pharmacokinetics of WR 238605, a new antimalarial. Am J Trop Med Hyg. 1998;58(5):645-649.

70. Green JA, Patel AK, Patel BR, et al. Tafenoquine at therapeutic concentrations does not prolong fridericia-corrected QT interval in healthy subjects. J Clin Pharmacol. 2014;54(9):995-1005.

71. Edstein MD, Kocisko DA, Walsh DS, Eamsila C, Charles BG, Rieckmann KH. Plasma concentrations of tafenoquine, a new longacting antimalarial agent, in Thai soldiers receiving monthly prophylaxis. Clin Infect Dis. 2003;37(12):1654-1658.

72. Edstein MD, Kocisko DA, Brewer TG, Walsh DS, Eamsila C, Charles BG. Population pharmacokinetics of the new antimalarial agent tafenoquine in Thai soldiers. Br J Clin Pharmacol. 2001;52(6): 663-670.

73. Edstein MD, Nasveld PE, Kocisko DA, Kitchener SJ, Gatton ML, Rieckmann KH. Gender differences in gastrointestinal disturbances and plasma concentrations of tafenoquine in healthy volunteers after tafenoquine administration for post-exposure vivax malaria prophylaxis. Trans R Soc Trop Med Hyg. 2007;101(3):226-230.
74. Li Q, O’Neil M, Xie L, et al. Assessment of the prophylactic activity and pharmacokinetic profile of oral tafenoquine compared to primaquine for inhibition of liver stage malaria infections. Malar J. 2014; 13(1): 141

75. Pybus BS, Marcsisin SR, Jin X, et al. The metabolism of primaquine to its active metabolite is dependent on CYP 2D6. Malar J. 2013; 12(1):212

76. Marcsisin SR, Sousa JC, Reichard GA, et al. Tafenoquine and NPC1161B require CYP 2D metabolism for anti-malarial activity: implications for the 8-aminoquinoline class of anti-malarial compounds. Malar J. 2014;13(1):2.

77. Vuong C, Xie LH, Potter BB, et al. Differential CYP 2D metabolism alters tafenoquine pharmacokinetics. Antimicrob Agents Chemother. 2015; 59(7):3864-3869.

78. Vennerstrom JL, Nuzum EO, Miller RE, et al. 8-Aminoquinolines active against blood stage Plasmodium falciparum in vitro inhibit hematin polymerization. Antimicrob Agents Chemother. 1999;43(3):598-602.

79. Pradines B, Mamfoumbi MM, Tall A, et al. In vitro activity of tafenoquine against the asexual blood stages of Plasmodium falciparum isolates from Gabon, Senegal, and Djibouti. Antimicrob Agents Chemother. 2006;50(9):3225-3226.

80. Ponsa N, Sattabongkot J, Kittayapong P, Eikarat N, Coleman RE. Transmission-blocking activity of tafenoquine (WR-238605) and artelinic acid against naturally circulating strains of Plasmodium vivax in Thailand. Am J Trop Med Hyg. 2003;69(5):542-547.

81. Research Councils UK [webpage on the Internet]. Defining the Mechanism of Action of the 8-Aminoquinolines: A Pre-Requisite to Rationally Designed Safe Antimalarials for the Elimination Era. Available from: http://gtr.rcuk.ac.uk/projects?ref=MR/L000644/1. Accessed April 13, 2016.

82. Malaria Nexus [webpage on the Internet]. Tafenoquine Gets a U.S. Food and Drug Administration (FDA) Breaththrough Therapy Designation. 2014. Available from: http://www.malarianexus.com/news/ tafenoquine-gets-u-s-food-and-drug-administration-fda-breakthrough/. Accessed May 23, 2016.

83. Center for Health Policy [webpage on the Internet]. Breakthrough Therapy Designation: Exploring the Qualifying Criteria. 2015. Available from: http://www.brookings.edu/events/2015/04/24-fdabreakthrough-therapy-criteria. Accessed May 23, 2016.

84. Beck HP, Wampfler R, Carter N, et al. Estimation of the antirelapse efficacy of tafenoquine, using Plasmodium vivax genotyping. J Infect Dis. 2016;213(5):794-799.

85. Llanos-Cuentas A, Lacerda MV, Rueangweerayut R, et al. Tafenoquine plus chloroquine for the treatment and relapse prevention of Plasmodium vivax malaria (DETECTIVE): a multicentre, double-blind, randomised, phase 2b dose-selection study. Lancet. 2014;383(9922):1049-1058.

86. Walsh DS, Looareesuwan S, Wilairatana P, et al. Randomized doseranging study of the safety and efficacy of WR 238605 (tafenoquine) in the prevention of relapse of Plasmodium vivax malaria in Thailand. J Infect Dis. 1999;180(4):1282-1287.

87. Walsh DS, Wilairatana P, Tang DB, et al. Randomized trial of 3-dose regimens of tafenoquine (WR238605) versus low-dose primaquine for preventing Plasmodium vivax malaria relapse. Clin Infect Dis. 2004; 39(8):1095-1103.

88. Edstein M, Walsh D, Eamsila C, et al. Malaria prophylaxis/radical cure: recent experiences of the Australian Defense Force. Med Trop. 2001;61(1):1-2.

89. Brueckner RP, Coster T, Wesche DL, Shmuklarsky M, Schuster BG. Prophylaxis of Plasmodium falciparum infection in a human challenge model with WR 238605, a new 8-aminoquinoline antimalarial. Antimicrob Agents Chemother. 1998;42(5):1293-1294.

90. Hale BR, Owusu-Agyei S, Fryauff DJ, et al. A randomized, double-blind, placebo-controlled, dose-ranging trial of tafenoquine for weekly prophylaxis against Plasmodium falciparum. Clin Infect Dis. 2003;36(5): 541-549.

91. Shanks GD, Oloo AJ, Aleman GM, et al. A new primaquine analogue, tafenoquine (WR 238605), for prophylaxis against Plasmodium falciparum malaria. Clin Infect Dis. 2001;33(12):1968-1974. 
92. Lell B, Faucher JF, Missinou MA, et al. Malaria chemoprophylaxis with tafenoquine: a randomised study. Lancet. 2000;355(9220):2041-2045.

93. Nasveld PE, Edstein MD, Reid M, et al. Randomized, double-blind study of the safety, tolerability, and efficacy of tafenoquine versus mefloquine for malaria prophylaxis in nonimmune subjects. Antimicrob Agents Chemother. 2010;54(2):792-798.

94. Elmes NJ, Nasveld PE, Kitchener SJ, Kocisko DA, Edstein MD. The efficacy and tolerability of three different regimens of tafenoquine versus primaquine for post-exposure prophylaxis of Plasmodium vivax malaria in the Southwest Pacific. Trans R Soc Trop Med Hyg. 2008; 102(11):1095-1101

95. Nasveld P, Kitchener S, Edstein M, Rieckmann K. Comparison of tafenoquine (WR238605) and primaquine in the post-exposure (terminal) prophylaxis of vivax malaria in Australian Defense Force personnel. Trans R Soc Trop Med Hyg. 2002;96(6):683-684.
96. Nasveld P, Kitchener S. Treatment of acute vivax malaria with tafenoquine. Trans R Soc Trop Med Hyg. 2005;99(1):2-5.

97. Kitchener S, Nasveld P, Edstein MD. Short report: tafenoquine for the treatment of recurrent Plasmodium vivax malaria. Am J Trop Med Hyg. 2007;76(3):494-496.

98. Walsh D, Eamsila C, Sasiprapha T, et al. Efficacy of monthly tafenoquine for prophylaxis of Plasmodium vivax and multidrugresistant Plasmodium falciparum malaria. J Infect Dis. 2004;190(8): 1456-1463.

99. PubChem [webpage on the Internet]. Primaquine: Compound Summary for CID 4908. 2005. Available from: https://pubchem.ncbi.nlm.nih.gov/ compound/primaquine. Accessed May 23, 2016.

\section{Publish your work in this journal}

Drug Design, Development and Therapy is an international, peerreviewed open-access journal that spans the spectrum of drug design and development through to clinical applications. Clinical outcomes, patient safety, and programs for the development and effective, safe, and sustained use of medicines are a feature of the journal, which has also been accepted for indexing on PubMed Central. The manuscript management system is completely online and includes a very quick and fair peer-review system, which is all easy to use. Visit http://www.dovepress.com/testimonials.php to read real quotes from published authors.

Submit your manuscript here: http://www.dovepress.com/drug-design-development-and-therapy-journal 